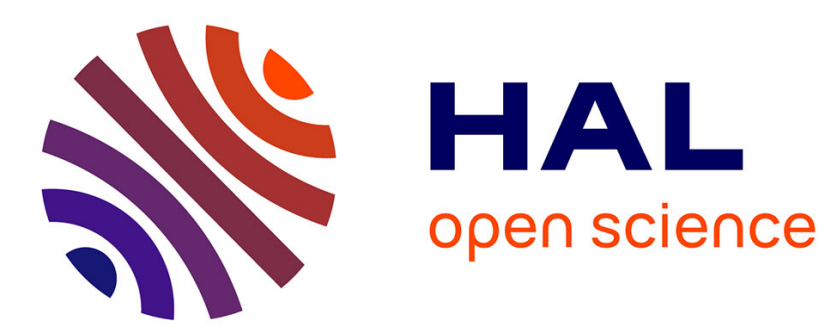

\title{
Core field acceleration pulse as a common cause of the 2003 and 2007 geomagnetic jerks
}

\author{
A. Chulliat, Erwan Thébault, Gauthier Hulot
}

\section{To cite this version:}

A. Chulliat, Erwan Thébault, Gauthier Hulot. Core field acceleration pulse as a common cause of the 2003 and 2007 geomagnetic jerks. Geophysical Research Letters, 2010, 37 (7), pp.L07301. 10.1029/2009GL042019 . insu-01285705

\section{HAL Id: insu-01285705 https://hal-insu.archives-ouvertes.fr/insu-01285705}

Submitted on 10 Mar 2016

HAL is a multi-disciplinary open access archive for the deposit and dissemination of scientific research documents, whether they are published or not. The documents may come from teaching and research institutions in France or abroad, or from public or private research centers.
L'archive ouverte pluridisciplinaire HAL, est destinée au dépôt et à la diffusion de documents scientifiques de niveau recherche, publiés ou non, émanant des établissements d'enseignement et de recherche français ou étrangers, des laboratoires publics ou privés. 


\title{
Core field acceleration pulse as a common cause of the 2003 and 2007 geomagnetic jerks
}

\author{
A. Chulliat, ${ }^{1}$ E. Thébault, ${ }^{1}$ and G. Hulot ${ }^{1}$ \\ Received 2 December 2009; revised 22 February 2010; accepted 2 March 2010; published 1 April 2010.
}

[1] Using observatory data, we report the detection of a geomagnetic jerk in 2007, which we relate to a jump in the second derivative of the geomagnetic field previously noted in satellite data. Although not of worldwide extent, this jerk is very intense in the South Atlantic region. Using the CHAOS-2 model, we show that both this jerk and the previous 2003 jerk are caused by a single core field acceleration pulse reaching its maximum power near 2006.0. This pulse seems to be simultaneously occurring in several regions of the core surface where it corresponds to dominant $n=5$ and 6 spherical harmonic modes. Geometrical attenuation explains why the 2003 and 2007 jerks are local and not fully synchronized at the Earth's surface. Our results suggest that this core field acceleration pulse is the relevant phenomenon to be investigated from the point of view of core dynamics, rather than the jerks themselves. Citation: Chulliat, A., E. Thébault, and G. Hulot (2010), Core field acceleration pulse as a common cause of the 2003 and 2007 geomagnetic jerks, Geophys. Res. Lett., 37, L07301, doi:10.1029/2009GL042019.

\section{Introduction}

[2] The main part of the geomagnetic field originates in the Earth's outer core and varies on secular time scales. Geomagnetic jerks are abrupt changes in the trend of this secular variation, i.e., jumps in the second derivative of the main field recorded at magnetic observatories [Courtillot et al., 1978]. Several jerks are known to have occurred in the 20th and 21th centuries, the most recent ones in 1991 [Macmillan, 1996], 1999 [Mandea et al., 2000] and 2003 [Olsen and Mandea, 2007]. They have been widely studied and their internal origin is now firmly established [e.g., Jackson and Finlay, 2007]. However, the physical origin of jerks is not yet elucidated, despite attempts to provide interpretations in terms of torsional oscillations [Bloxham et al., 2002], core flows [Le Huy et al., 1998; Wardinski et al., 2008] and boundary layers instabilities [Desjardins et al., 2001]. Some jerks are worldwide in occurrence while some others are not, and all occur within differential time delays of about two years at the Earth's surface [Alexandrescu et al., 1996].

[3] Recently, Olsen et al. [2009] detected 'a sudden jump in the second time derivative' around 2007 in satellite data and CHAOS-2, a new spherical harmonic model of the core field covering the time interval 1997-2009. This event is

\footnotetext{
${ }^{1}$ Equipe de Géomagnétisme, Institut de Physique du Globe de Paris, Université Paris Diderot, INSU, CNRS, Paris, France.

Copyright 2010 by the American Geophysical Union. 0094-8276/10/2009GL042019
}

seen west of Africa in their Figure 7. In the present paper we will analyze this event in more details, based on both observatory data and the CHAOS-2 model, and show that it indeed qualifies as a geomagnetic jerk in very much the same way as the 2003 geomagnetic jerk. Then we will show that both jerks are actually caused by the same field acceleration pulse at the core surface reaching its maximum near 2006.0. This result suggests that this acceleration pulse is the relevant geophysical phenomenon to be investigated from the point of view of core dynamics, while the 2003 and 2007 jerks are only geometrical effects of the upward continuation of the field from the core to the Earth's surface.

\section{Signature of the 2007 Jerk at the Earth's Surface}

[4] Figure 1 shows the annual differences of monthly means of the $Y$ and $Z$ components at five magnetic observatories from 1997 to 2009. The observatories are listed in Table 1. Annual differences are differences between monthly means at times $t+6$ months and $t-6$ months. Taking annual differences removes the annual variation caused by the external field sources in the monthly means [e.g., Olsen and Mandea, 2007]. Monthly means until December 2008 were calculated from 1-minute values provided by INTERMAGNET (www.intermagnet.org). For three observatories (Kourou, MBour and Tamanrasset), we also used quasi-definitive data, defined as baseline corrected data very close to the final data [Peltier and Chulliat, 2010]. Such data allowed the calculation of monthly means until October 2009.

[5] On the $Y$ component, there is an abrupt change in the secular variation trend near 2007.0 at MBO, ASC and TSU, near 2008.0 at KOU, and near 2006.0 at TAM. The largest change is seen at $\mathrm{MBO}$, where the secular variation decreases from $70 \mathrm{nT} / \mathrm{yr}$ to $50 \mathrm{nT} / \mathrm{yr}$ in two years and then increases back to $70 \mathrm{nT} / \mathrm{yr}$ in two years, corresponding to an acceleration change of about $20 \mathrm{nT} / \mathrm{yr}^{2}$ in 2007 . This is about four times larger than the acceleration change recorded in Niemegk (NGK) observatory during the widely studied 1979 jerk, when the secular acceleration changed from $2.5 \mathrm{nT} / \mathrm{yr}^{2}$ (during the $1970 \mathrm{~s}$ ) to $-2 \mathrm{nT} / \mathrm{yr}^{2}$ (during the 1980 s). On the $Z$ component, the jerk signal is conspicuous in all five observatories near 2007.0. The change in acceleration is maximum at ASC, reaching about $20 \mathrm{nT} / \mathrm{yr}^{2}$ after three years of very steep decrease of the secular variation from $-80 \mathrm{nT} / \mathrm{yr}$ to almost $-130 \mathrm{nT} / \mathrm{yr}$. A very large change also occurred at $\mathrm{KOU}$, where the secular variation has been decreasing by more than $30 \mathrm{nT} / \mathrm{yr}$ since 2007 .

[6] One should be cautious in interpreting time variations of annual differences, as observatory monthly means are contaminated by geomagnetic activity of external origin. 

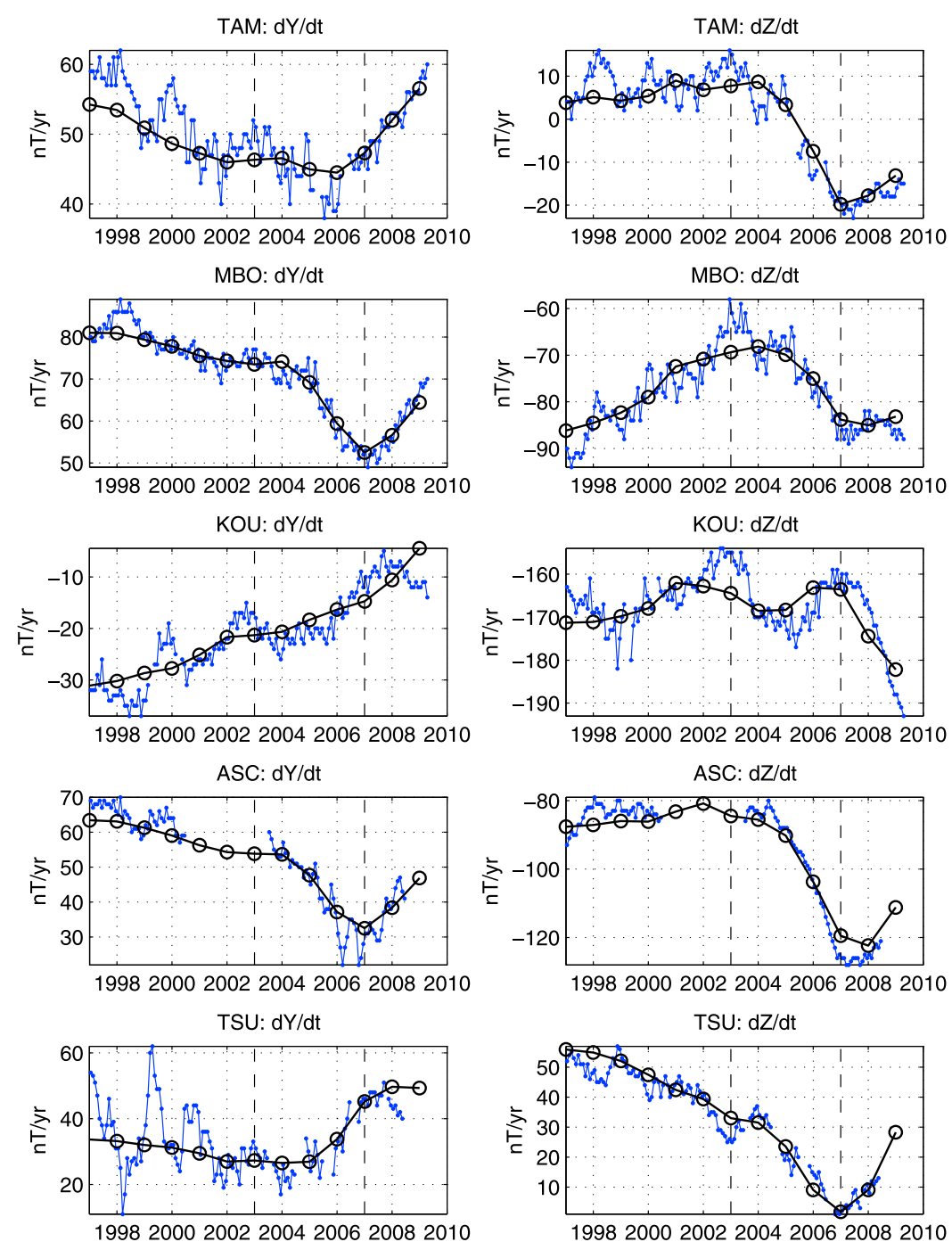

Figure 1. Annual differences (blue dots) of the $\mathrm{Y}$ and $\mathrm{Z}$ components at the observatories listed in Table 1, ordered from North to South. The secular variation calculated from the CHAOS-2 model is represented by black lines and circles. Dashed vertical lines indicate the dates of the 2003 and 2007 jerks.

This contamination is particularly large on the $X$ component, due to the geometry of the auroral electrojets and equatorial electrojet, and for this reason we do not show this component in Figure 1. However, on the $Y$ and $Z$ components, external field effects lead to high-frequency variations of much smaller amplitudes than those of the observed acceleration changes. We conclude that a geomagnetic jerk actually occurred between 2006.0 and 2008.0 at all considered observatories. In what follows we will refer to this jerk as the '2007 jerk'.

[7] Also represented in Figure 1 is the secular variation predicted by the CHAOS- 2 spherical harmonic model [Olsen et al., 2009] at observatory locations. This model is based upon ten years of Ørsted satellite data (March 1999March 2009), almost nine years of CHAMP satellite data (August 2000-March 2009), four years of SAC-C data (January 2001-December 2004) and annual differences of observatory monthly means from 1997 to 2006. In Figure 1 we used the CHAOS-2s version of the model, not the lessregularized CHAOS-2r version. The 2007 jerk is conspic- uous in the model signal at all observatories where it is detected in the data, except on the $Y$ component at KOU and, to a lesser extent, TSU. These differences could be due to the lack of observatory data in the model dataset after 2006 or to an edge effect of the spline representation used for CHAOS-2. However, the overall agreement between observatory data and CHAOS-2 at selected observatories during the 2007 jerk is excellent and suggests that this

Table 1. List of the Magnetic Observatories Used in Figure 1 With Their IAGA Codes and Positions

\begin{tabular}{lccc}
\hline \multicolumn{1}{c}{ Name } & Code & Latitude $\left(^{\circ}\right)$ & Longitude $\left(^{\circ}\right)$ \\
\hline Ascension & ASC & -7.9 & 345.6 \\
Kourou & KOU & 5.21 & 307.27 \\
MBour & MBO & 14.39 & 343.04 \\
Tamanrasset & TAM & 22.79 & 5.53 \\
Tsumeb & TSU & -19.20 & 17.58 \\
\hline
\end{tabular}


a
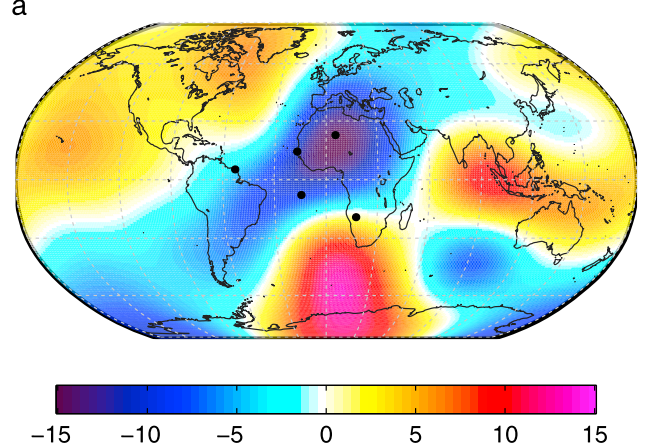

b
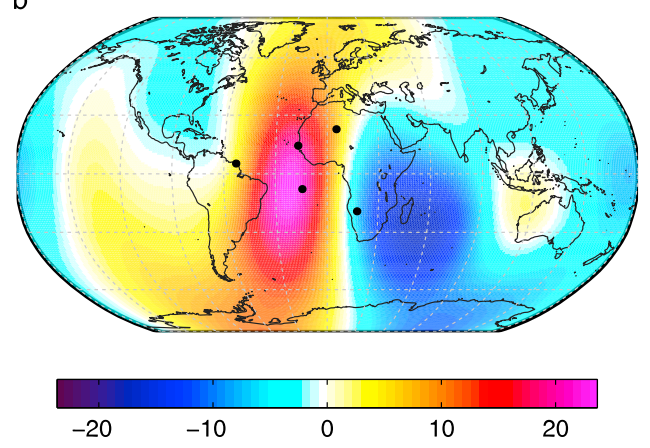

C

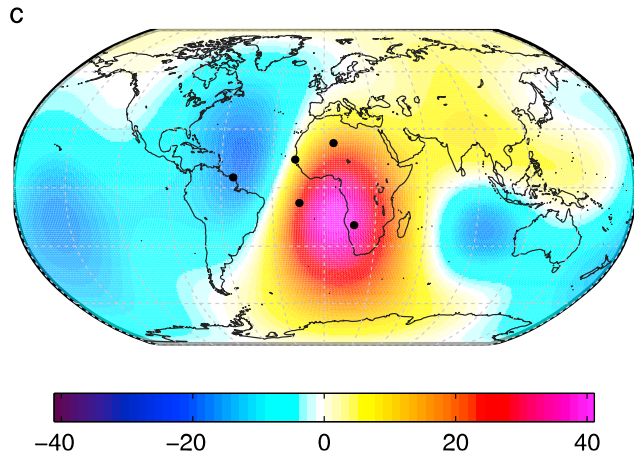

Figure 2. Maps of (a) $\Delta \ddot{X}$, (b) $\Delta \ddot{Y}$ and (c) $\Delta \ddot{Z}$ at epoch 2007 at the Earth's surface from the CHAOS-2 model. Black dots indicate the positions of observatories listed in Table 1. Unit: $\mathrm{nT} / \mathrm{yr}^{2}$.

model can be used to investigate the global structure of the jerk.

[8] Following the method used by Olsen and Mandea [2007] to characterize the geographical extent of the 2003 jerk, we map the acceleration change on each component between $t_{1}=2005.5$ and $t_{2}=2008.5$, given by

$$
\Delta \ddot{X}=\left.\ddot{X}\right|_{t_{2}}-\left.\ddot{X}\right|_{t_{1}},
$$

and similar formulas for $Y$ and $Z$ (Figure 2). The maximum jerk signal is found: on $X$, in Western Africa and the South Atlantic Ocean; on $Y$, in the equatorial part of the Atlantic Ocean and the southwestern part of the Indian Ocean; on $Z$, in southern Africa and the South Atlantic Ocean. The jerk is strongest on the $Z$ component. Note that the observatories listed in Table 1 are located in areas where the amplitude of the 2007 jerk is maximum, either on $Y, Z$ or both. We conclude that the 2007 jerk is not worldwide in occurrence. This is similar to the previous jerk in 2003, which was maximum in Eastern Asia and Australia [see Olsen and Mandea, 2007, Figure 7].

\section{Field Acceleration Pulse at the Core Surface}

[9] Neglecting the electrical conductivity of the mantle, we downward continue the CHAOS-2 model (CHAOS-2s version) to the core-mantle boundary (CMB). Unlike horizontal components, the radial component $B_{r}$ of the field is continuous through the $\mathrm{CMB}$. The acceleration change on that component, obtained from equation (1) for the 2003 jerk (by taking $t_{1}=2001.5$ and $t_{2}=2004.5$ ) and the 2007 jerk, is represented at the core surface in Figures $3 \mathrm{a}$ and $3 \mathrm{c}$.

[10] Although the amplitude of the acceleration change is smaller in 2003 than in 2007, the positive and negative patches at both epochs are mainly anti-correlated. This striking feature is observed all over the core surface, in the equatorial region as well as near the poles. In 2003, the largest absolute acceleration change is found under Cocos Islands (eastern Indian Ocean, near $20^{\circ} \mathrm{S}, 90^{\circ} \mathrm{E}$ ), where it

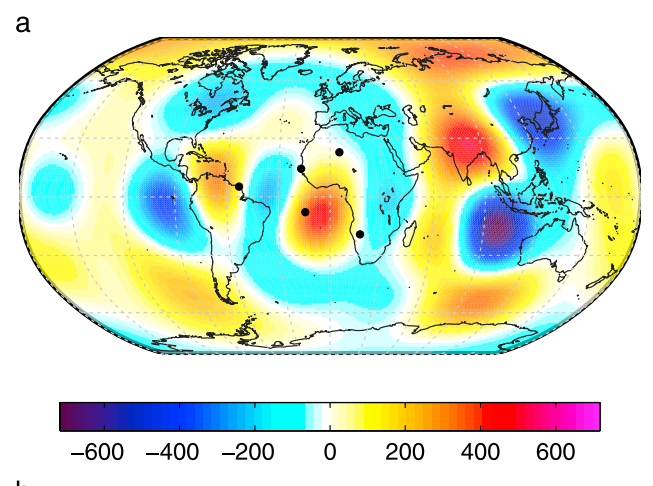

b
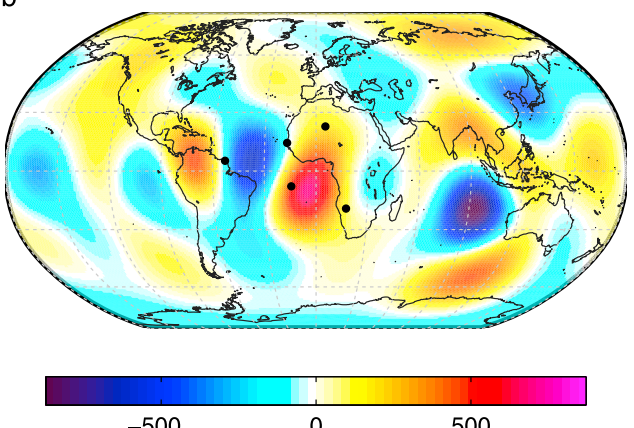

C

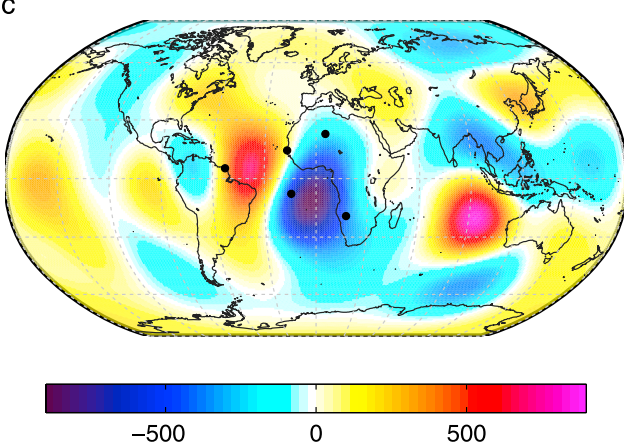

Figure 3. Maps of (a) $\Delta \ddot{B}_{r}$ at epoch 2003, (b) $\ddot{B}_{r}$ at epoch 2005 and (c) $\Delta \ddot{B}_{r}$ at epoch 2007 at the core surface from the CHAOS-2 model. Black dots indicate the positions of observatories listed in Table 1. Unit: $\mathrm{nT} / \mathrm{yr}^{2}$. 


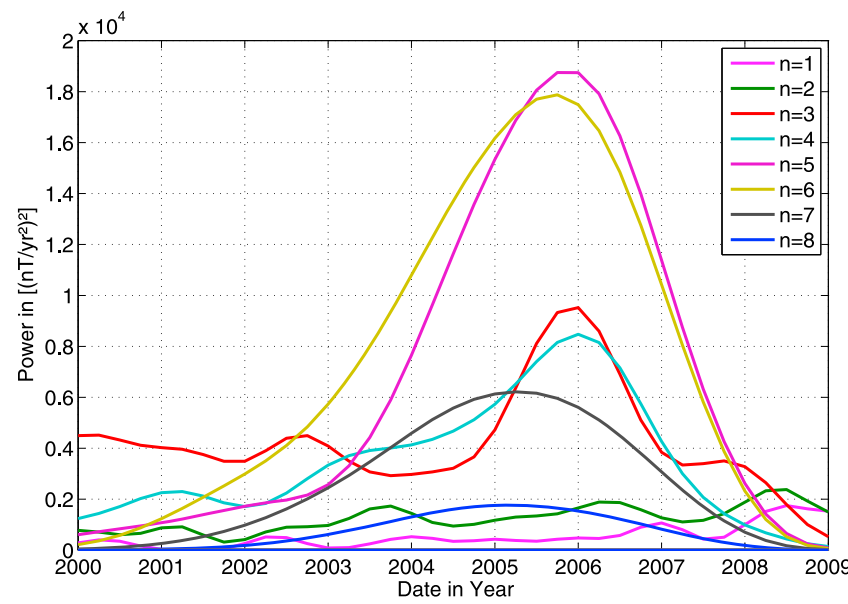

Figure 4. Time variation of the squared acceleration power (in $\left.\left(\mathrm{nT} / \mathrm{yr}^{2}\right)^{2}\right)$ of each degree $n$ of CHAOS-2 at the CMB.

reaches about $-500 \mathrm{nT} / \mathrm{yr}^{2}$, and there is a secondary maximum under St Helena Island (South Atlantic Ocean, near $\left.10^{\circ} \mathrm{S}, 0^{\circ} \mathrm{E}\right)$, reaching about $300 \mathrm{nT} / \mathrm{yr}^{2}$. In 2007 , the absolute maximum is found both under St Helena Island (about $-800 \mathrm{nT} / \mathrm{yr}^{2}$ ) and Cocos Islands (about $800 \mathrm{nT} / \mathrm{yr}^{2}$ ).

[11] This anti-correlation results from the fact that $\ddot{B}_{r}$ is actually much more powerful between 2003 and 2007 than outside this time interval. This can be checked by plotting $\ddot{B}_{r}$ on the whole time interval 1997-2009 (not shown). The maximum is reached between 2005.5 and 2006.0. It follows that the spatial structure of the radial acceleration at epoch 2005.5 (Figure $3 b$ ) is very close to that of $\Delta \ddot{B}_{r}$ at epochs 2003.0 (Figure 3a) and 2007.0 (Figure 3c), to within a sign. The two jerks, 2003 and 2007, occur as the ascending and descending phases of the intense acceleration observed in 2005. The largest accelerations in 2005 are found under St Helena and Cocos Islands, but other patches grow and decay over the same time interval: under Japan, the Pacific Ocean, South America. Thus the geographical extent of the pulse is very large. We also note that the general spatial structure of $\ddot{B}_{r}$, i.e., the locations and sizes of the most intense patches, is very stable between 2003 and 2007, suggesting a mainly non-propagating process.

[12] The acceleration 'pulse' between 2003 and 2007 is actually best seen by plotting the time variation of the power of each degree $n$ at the CMB (Figure 4). It occurs between 2005.5 and 2006.0 for degrees $n=3$ to 7 , and is maximum for $n=5$ and 6 . It is worth noting that the first six degrees of the secular acceleration of CHAOS-2 (in its CHAOS-2s version, which we use in this paper) have been shown to be robust by Olsen et al. [2009] and that the larger spread for the higher degrees is likely caused by the stronger temporal regularization of these degrees in CHAOS-2. We further note that the modes $n=3$ to 7 roughly peak at the same time. The reason why this pulse cannot be seen as clearly in observatories at the Earth's surface is that the $n=5$ and 6 modes are geometrically attenuated by the distance to the core surface. In fact the same plot as in Figure 4 but at the Earth's surface (not shown) shows the acceleration pulse, but its power is much smaller than that of the degrees $n=1$ and 2 , which do not contribute to the pulse.
[13] The way the acceleration pulse best manifests itself at the Earth's surface is by generating jerks before and after its peak at well-defined locations. This is best understood by considering the Green's functions $G_{X}, G_{Y}$ and $G_{Z}$ relating $B_{r}$ at the core surface and $X, Y$ and $Z$ at the Earth's surface [Constable et al., 1993; Chulliat et al., 2010]:

$$
X(\mathbf{r}, t)=\int_{S} G_{X}(\mathbf{r}, \hat{\mathbf{s}}) B_{r}(\hat{\mathbf{s}}, t) d^{2} \hat{\mathbf{s}}
$$

and similar formulas for $Y$ and $Z$. Here $\mathbf{r}$ is the position vector at the Earth's surface, and $\hat{\mathbf{s}}$ is a unit radial vector defining the location at the core surface over which the integral runs. For a given point $P$ at the Earth's surface and $P_{C M B}$ its vertical projection at the core surface, $G_{Z}$ is maximum and negative at $P_{C M B}$ and its absolute value regularly decreases away from this point. This explains why $\Delta \ddot{Z}$ (Figure 2c) is maximum right above the maximum in $\Delta \ddot{B}_{r}$ (Figure $3 \mathrm{c}$ ), but of opposite sign. The size of the corresponding patch of negative $\Delta \ddot{B}_{r}$ is large enough to positively contribute to $\Delta \ddot{Z}$ above the secondary maximum (in the eastern Indian Ocean), hence the smaller absolute value of $\Delta \ddot{Z}$ there. Unlike $G_{Z}, G_{X}$ and $G_{Y}$ consist of two lobes of opposite polarities centered about $25^{\circ}$ away from $P_{C M B}$ in the direction parallel to $X$ and $Y$, respectively [see Chulliat et al., 2010, Figure 6c], thus explaining the positions of the maxima in Figures $2 a-2 b$. Note that the observatories listed in Table 1 are located over areas of small $\Delta \ddot{B}_{r}$ in 2003 , hence a small or even no jerk signature on the $Z$ component (Figure 1).

[14] We conclude that the 2003 and 2007 jerks are Earth's surface manifestations of a large acceleration pulse at the core surface reaching its maximum near 2006. This pulse seems to be simultaneously occurring in several places distributed all over the core surface, but the associated jerks are local and not fully synchronized at the Earth's surface, due to the geometrical attenuation of the field between the core surface and the Earth's surface.

[15] Based on an analysis of the 1969, 1979 and 1991 jerks, Le Huy et al. [1998] already noted an anti-correlation between the Earth's surface signatures of two successive jerks. With the hindsight provided by the present study, this again suggests that jerks are produced in pairs as a result of a common field acceleration event, the pulse we observe in 2006 being particularly remarkable in terms of magnitude and spatio-temporal sharpness. It will be interesting to test whether this pulse is compatible with mechanisms such as torsional oscillations [Bloxham et al., 2002] (but see, e.g., Olsen and Mandea [2007] and Wardinski et al. [2008] for a criticism), that have previously been proposed to account for jerks.

[16] Acknowledgments. The results presented in this paper rely on data collected at magnetic observatories. We thank the national institutes that support them and INTERMAGNET for promoting high standards of magnetic observatory practice (www.intermagnet.org). We thank two anonymous reviewers for their help in clarifying the manuscript. The research reported here was financially supported by CNES. This is IPGP contribution 2619

\section{References}

Alexandrescu, M., D. Gibert, G. Hulot, J.-L. Le Mouël, and G. Saracco (1996), Worldwide wavelet analysis of geomagnetic jerks, J. Geophys. Res., 101, 21,975-21,994. 
Bloxham, J., S. Zatman, and M. Dumberry (2002), The origin of geomagnetic jerks, Nature, 420, 65-68.

Chulliat, A., G. Hulot, and L. R. Newitt (2010), Magnetic flux expulsion from the core as a possible cause of the unusually large acceleration of the North magnetic pole during the 1990s, J. Geophys. Res., doi:10.1029/2009JB007143, in press.

Constable, C. G., R. L. Parker, and P. Stark (1993), Geomagnetic field models incorporating frozen-flux constraints, Geophys. J. Int., 113, 419-433.

Courtillot, V., J. Ducruix, and J.-L. Le Mouël (1978), Sur une accélération récente de la variation séculaire du champ magnétique terrestre, $C$. $R$. Acad. Sci., Ser. D, 287, 1095-1098.

Desjardins, E., E. Dormy, and E. Grenier (2001), Instability of EkmanHartmann boundary layers, with application to the fluid flow near the core-mantle boundary, Phys. Earth Planet. Inter., 123, 15-26.

Jackson, A., and C. C. Finlay (2007), Geomagnetic Secular Variation and Its Applications to the Core, in Treatise on Geophysics, vol. 5, edited by M. Kono and G. Schubert, pp. 147-193, Elsevier, New York.

Le Huy, M., M. Alexandrescu, G. Hulot, and J.-L. Le Mouël (1998), On the characteristics of successive geomagnetic jerks, Earth Planets Space, $50,723-732$.
Macmillan, S. (1996), A geomagnetic jerk for the early 1990's, Earth Planet. Sci. Lett., 137, 189-192.

Mandea, M., E. Bellanger, and J.-L. Le Mouël (2000), A geomagnetic jerk for the end of the 20th century?, Earth Planet. Sci. Lett., 183, 369-373.

Olsen, N., and M. Mandea (2007), Investigation of a secular variation impulse using satellite data: The 2003 geomagnetic jerk, Earth Planet. Sci. Lett., 255, 94-105.

Olsen, N., M. Mandea, T. J. Sabaka, and L. Tøffner-Clausen (2009), CHAOS-2 - A geomagnetic field model derived from one decade of continuous satellite data, Geophys. J. Int., 179, 1477-1487.

Peltier, A., and A. Chulliat (2010), On the feasibility of promptly producing quasi-definitive magnetic observatory data, Earth Planets Space, 62, e5-e8, doi:10.5047/eps.2010.02.002.

Wardinski, I., R. Holme, S. Asari, and M. Mandea (2008), The 2003 geomagnetic jerk and its relation to the core surface flows, Earth Planet. Sci. Lett., 267, 468-481.

A. Chulliat, G. Hulot, and E. Thébault, Equipe de Géomagnétisme, Institut de Physique du Globe de Paris, Université Paris Diderot, INSU, CNRS, 4 place Jussieu, F-75005 Paris, France. (chulliat@ipgp.fr; gh@ ipgp.fr; ethebault@ipgp.fr) 